\title{
Patient preferences for asthma therapy: a discrete choice experiment
}

\author{
*Andrew Lloyda, Emma McIntosh ${ }^{b}$, Klaus F Rabec, Angela Williams ${ }^{d}$ \\ a Deputy Director Europe, United BioSource Corporation, 20 Bloomsbury Square, London, WC1A 2NS, UK \\ ${ }^{b}$ Senior Research Officer, Health Economics Research Centre, Department of Public Health, University of Oxford, UK \\ Chairman and Head, Department of Pulmonology, Leiden University Medical Centre, Netherlands \\ 'Senior Health Outcomes Manager, Global Health Outcomes, GlaxoSmithKline, Greenford, UK
}

Received 8th February 2007; accepted 20th June 2007

\begin{abstract}
Aim: This study was designed to capture patient preferences for different aspects of asthma treatment from people with asthma in the UK, the Netherlands and Spain.

Methods: Asthma patients from the UK $(n=124)$, the Netherlands $(n=269)$ and Spain $(n=86)$ participated in the survey. Patients' preferences and willingness to pay for a particular number of preventer inhalers, in relation to days per week with symptoms, days requiring reliever medication, risk of side effects, and requirement for a visit to their general practitioner (GP) or the Emergency Room (ER), were recorded.

Results: Participants were willing to pay $€ 35 /$ month to avoid a day with symptoms, $€ 109 /$ month to avoid asthma attacks that required emergency visits to their GP or the ER, and $€ 94 /$ month to achieve total avoidance of asthma symptoms compared with their current state. Conclusions: This study presents European data regarding the importance to patients of different attributes of asthma and its treatment. Study participants placed high values on the avoidance of symptoms, and asthma attacks requiring medical attendance.

(C) 2007 General Practice Airways Group. All rights reserved.

A Lloyd, et al. Prim Care Resp J 2007; 16(4): 241-248.

doi:10.3132/pcrj.2007.00052
\end{abstract}

Keyw ords asthma, patient preferences, willingness to pay, discrete choice experiment

\section{Introduction}

The Global Initiative for Asthma (GINA) has produced guidelines for the management of asthma, ${ }^{1}$ and these guidelines are updated annually and revised to reflect developments in the evidence base. The GINA guidelines describe the aim of asthma management as being the achievement and maintenance of asthma control. They highlight a number of aspects of asthma management; however, they do not account for those aspects which are most important to patients. European surveys indicate that few patients achieve guideline-defined asthma control.2,3 Consequently, asthma remains a significant burden, ${ }^{4}$ is a leading cause of lost school and work days, ${ }^{5}$ and has a significant impact on health-related quality of life. ${ }^{6}$

Systematic attempts to understand the preferences of asthma patients have been reported previously. Osman et al reported that asthma patients were willing to trade higher levels of wheeze and sleep disturbance in order to avoid cough and breathlessness. ' Zillich et al reported that patients with the greatest burden of asthma (as measured by quality of life questionnaires) were willing to pay the most for a hypothetical asthma 'cure', ${ }^{\prime}$ participants classified as mild were willing to pay \$US48 per month, whereas participants who were classified as severe were willing to pay $\$$ US241 per month. Johannsson et al explored asthma patients' preferences for the type of maintenance treatment, number of inhalers, speed and duration of symptom relief, and symptom-free days (SFDs). ${ }^{9}$ The number of SFDs was the most important attribute for patients; $85 \%$ of patients preferred an alternative treatment over their current treatment and were prepared to pay extra for it - but the analyses did not indicate reliably participants' willingness to pay for improvements. Most recently, King et $\mathrm{al}^{10}$ reported a

\footnotetext{
* Corresponding author: Tel: +44 (0)207 2994558 Fax: +44 (0)207 2994555 E-mail: Andrew.Lloyd@unitedbiosource.com
} 
study which embedded a discrete choice experiment (DCE) survey within a clinical trial of asthma patients. This study found that most respondents chose to continue with their current drug in most choice situations but this tendency differed depending on which medication they had been allocated. Participants valued being able to participate in usual daily activities and sport, and preferred minimal symptoms. This was a relatively small survey of 52 people which may explain why not all attributes emerged as predictors of choice.

Some information has emerged from the literature regarding the importance of different aspects of asthma therapy, and the attributes of asthma therapy included in this study were derived directly from asthma patients and reflect recommendations in the GINA guidelines.

This study was designed to address some of the shortcomings of previous studies and to advance our understanding of patient preferences for asthma therapy; in particular, we have been able to estimate the monetary value placed on achieving better asthma control. In doing so, the strength of preference for alternative attributes of asthma management may be successfully quantified. There are an increasing number of papers in the literature on the methodology required to estimate patients' willingness to pay within discrete choice experiments. ${ }^{11-21}$

\section{Methods}

A stated preference DCE was designed to elicit patient preferences for different aspects of asthma therapy. The main aim of the study was to determine patients' strength of preference for control over their asthma.

\section{Study measures}

Discrete choice experiments (DCE) are a form of survey methodology which are widely used in health care to elicit the preferences of patients. ${ }^{22,23}$ The method characterises treatment interventions in terms of distinct attributes and levels (e.g. number of days with symptoms per week). ${ }^{24}$ DCE methods can also be used to estimate the marginal value, in terms of willingness to pay out of one's own pocket, for different aspects of asthma therapy. ${ }^{12}$ Respondents decide which combination of attributes and levels they prefer. Through a series of questions it is possible to establish the relative importance of attributes and the trade-offs that people are willing to make. This method was used to understand the value of the attributes of treatments for asthma.

\section{Development work}

Several phases of pilot work were undertaken. A draft list of ten attributes was developed through discussion with the study team including clinical experts. Ten attributes were considered to be too many to include in a survey because it would make decision-making very complex for study participants. Therefore, attributes that could not be related back to GINA guidelines, or purely clinical attributes such as $\mathrm{FEV}_{1}$ which are less meaningful for patients, were dropped from the list. Two focus groups were conducted (in the UK and The Netherlands) to discuss the draft attributes and levels.

The final list of asthma attributes that were selected

Box 1. Attributes and levels employed in the survey.

\begin{tabular}{|c|c|}
\hline Asthma symptoms & $\begin{array}{l}\text { You experience no symptoms at all } \\
\text { You experience symptoms on } 2 \text { days per week } \\
\text { You experience symptoms on } 5 \text { days per week }\end{array}$ \\
\hline Use of reliever medication & $\begin{array}{l}\text { No need for reliever medication on any day per week } \\
\text { You need your reliever medication on } 2 \text { days per week } \\
\text { You need your reliever medication on } 5 \text { days per week }\end{array}$ \\
\hline Asthma attacks & $\begin{array}{l}\text { You will not have an asthma attack in the next year } \\
\text { You will have asthma attacks occasionally in the next year, but they are never bad enough that you would } \\
\text { need to see a doctor } \\
\text { You will have asthma attacks occasionally in the next year, which are bad enough that you will need to } \\
\text { see your GP or visit the A\&E department at the hospital }\end{array}$ \\
\hline Side effects & $\begin{array}{l}\text { Your chance of suffering a side effect with this medication is very low ( } 1 \text { in a } 100 \text { or } 1 \% \text { ) } \\
\text { Your chance of suffering a side effect with this medication is low (1 in } 10 \text { or } 10 \% \text { ) } \\
\text { Your chance of suffering a side effect with this medication is moderate ( } 1 \text { in a } 5 \text { or } 20 \% \text { ) }\end{array}$ \\
\hline Inhalers & $\begin{array}{l}\text { You require preventer treatment with one inhaler only } \\
\text { You require preventer treatment with two inhalers }\end{array}$ \\
\hline Monthly cost & $\begin{array}{l}£ 20 \\
£ 40 \\
£ 60\end{array}$ \\
\hline
\end{tabular}


included: number of days per week with symptoms; number of days per week you require reliever medication; severity of asthma attacks/exacerbations; risk of mild side effects (described as cough, tremor etc); number of preventer inhalers required, and out of pocket cost (see Box 1 for a description of the attributes and levels). The cost attribute is included in order to estimate willingness to pay for improvements in the other attributes. The UK cost attribute levels and household income levels were converted to equivalent Dutch- and Spanish-specific Euro $(€)$ rates using a purchasing power parity (PPP) calculation. Each attribute in the survey was described in two to three sentences and each attribute level was presented. The respondents were given pairwise choices based on an orthogonal design with foldover (as recommended by Louviere et $\mathrm{a}^{24}$ ) to ensure no overlap. This resulted in 21 choices, 18 from the orthogonal matrix plus 3 reliability and consistency checks.

The attributes and levels were combined into choice sets using an orthogonal design (http://www.research.att.com/ njas/oadir/\#3_2). Participants were presented with pairs of hypothetical treatments which described a specific level on each attribute, and were asked to state which they preferred (Figure 1). The DCE questionnaire also included questions regarding socio-demographics, income, some clinical information such as medication, and the mini-Asthma Quality of Life Questionnaire..25 The whole survey included the same 21 choice pairs, took about 30 minutes to complete, and participants were paid a nominal amount for taking part.

\section{Pilot studies}

Four asthma patients completed the survey in a 'think aloud' exercise, followed by a cognitive debrief interview to identify areas of misunderstanding. ${ }^{26}$ In addition, in a second pilot study, 31 asthma patients completed the draft survey and data were analysed to determine if attribute coefficients were all in the anticipated direction. No problems other than a few minor wording changes emerged from these pilot studies.

\section{Main study}

The main study was conducted at sites in The Netherlands, Spain and the UK. Rigorous translations of the questionnaires were produced using standardised methods for the translation of patient-reported outcomes. ${ }^{27}$ The UK cost attribute levels and household income levels were converted to equivalent Dutch- and Spanish-specific Euro $(€)$ rates using a purchasing power parity (PPP) calculation. This means that the results from each country are completely comparable in monetary terms.

Different approaches to recruitment were adopted in each country, which ensured a representative broad sample of patients with mainly mild-to-moderate asthma. In the UK study, participants were recruited via newspaper advertisements using a telephone screener (developed with a clinician) prior to being invited to take part. In The Netherlands,

\begin{tabular}{|c|c|c|}
\hline & Treatment A & Treatment B \\
\hline Asthma symptoms & $\begin{array}{l}\text { Symptoms } \\
2 \text { days } \\
\text { per week }\end{array}$ & $\begin{array}{l}\text { Symptoms } \\
5 \text { days } \\
\text { per week }\end{array}$ \\
\hline $\begin{array}{l}\text { Need for } \\
\text { reliever medication }\end{array}$ & $\begin{array}{l}\text { Reliever } \\
\text { medication } \\
5 \text { days } \\
\text { per week }\end{array}$ & $\begin{array}{c}\text { Reliever } \\
\text { medication } \\
2 \text { days } \\
\text { per week }\end{array}$ \\
\hline $\begin{array}{l}\text { Asthma attacks } \\
\text { in the next year }\end{array}$ & $\begin{array}{l}\text { Occasionally. } \\
\text { You do not } \\
\text { need to see } \\
\text { a doctor }\end{array}$ & $\begin{array}{l}\text { Occasionally. } \\
\text { you would need } \\
\text { to see a doctor } \\
\text { or visit A\&E }\end{array}$ \\
\hline $\begin{array}{l}\text { Chance of } \\
\text { side effects }\end{array}$ & $\begin{array}{c}\text { Moderate } \\
\text { chance. } 1 \text { in } 5 \\
\text { or } 20 \% \text { per year }\end{array}$ & $\begin{array}{l}\text { Low chance } \\
1 \text { in } 10 \\
\text { or } 10 \% \text { per year }\end{array}$ \\
\hline $\begin{array}{l}\text { Number of } \\
\text { preventer inhalers }\end{array}$ & 1 & 2 \\
\hline Cost to you per month & f60 & $f 40$ \\
\hline $\begin{array}{l}\text { Which would } \\
\text { you prefer? }\end{array}$ & $\square$ & $\square$ \\
\hline
\end{tabular}

patients were recruited through GP practices $(n=124)$, respiratory specialist outpatient clinics $(n=87)$ and through a Dutch patient advocacy group "Astma Fonds" $(n=58)$. In Spain, asthma patients were recruited through six pneumonologists' outpatient clinics. Patients signed an informed consent before answering the questionnaire.

To be eligible, participants had to have a diagnosis of asthma, be 18 to 75 years old, be able to read and understand English, Spanish or Dutch as appropriate, be willing and able to give informed consent, and had to pass the telephone screener questionnaire (UK only).

\section{Analysis}

Each choice that a respondent made was analysed as a data point. The DCE data were analysed using the random effects probit model in LIMDEP ${ }^{28}$ which accounts for multiple observations from the same individual. The choice responses were binary data and the regression model examined the extent to which each attribute predicted individuals' choices. From this analysis, willingness to pay for all attributes is estimated by taking the marginal rates of substitution between the attribute 'monthly cost of the drug' and the remaining attributes. Wald tests were used to test for differences in income subgroups.

\section{Results}

The characteristics of the study samples were summarised (Tables 1 \& 2). Three UK participants were removed from the 
Table 1. Socio-demographic profile of participants by country.

\begin{tabular}{|c|c|c|c|c|c|c|}
\hline & \multicolumn{2}{|c|}{ UK } & \multicolumn{2}{|c|}{ Spain } & \multicolumn{2}{|c|}{ The Netherlands } \\
\hline & $\mathrm{N}$ & $\%$ & $\mathrm{~N}$ & $\%$ & $\mathrm{~N}$ & $\%$ \\
\hline Sample size & 124 & & 86 & & 269 & \\
\hline Gender - \% male & 63 & 50.8 & 27 & 31.4 & 93 & 34.6 \\
\hline \multicolumn{7}{|l|}{ Ethnicity } \\
\hline White/ Caucasian & 106 & 85.5 & 86 & 100.0 & 257 & 95.9 \\
\hline Black/ Afro-Caribbean & 3 & 2.4 & & & 2 & 0.7 \\
\hline Asian & 8 & 6.5 & & & 3 & 1.1 \\
\hline Other & 7 & 5.6 & & & 5 & 1.9 \\
\hline \multicolumn{7}{|l|}{ Education } \\
\hline No formal qualifications & 16 & 12.9 & 25 & 29.1 & 25 & 9.3 \\
\hline Completed university & 34 & 27.4 & 15 & 17.4 & 19 & 7.1 \\
\hline \multicolumn{7}{|l|}{ Employment } \\
\hline Full time & 58 & 47.2 & 34 & 39.5 & 71 & 26.4 \\
\hline Median income & f20-30k & & $€ 18-36 k$ & & $€ 22-44 k$ & \\
\hline Mean age (std dev) & 41.8 & (14.9) & 46.9 & $(16.3)$ & 44.6 & $(15.6)$ \\
\hline
\end{tabular}

Table 2. Clinical, HRQL and smoking status of participants by country.

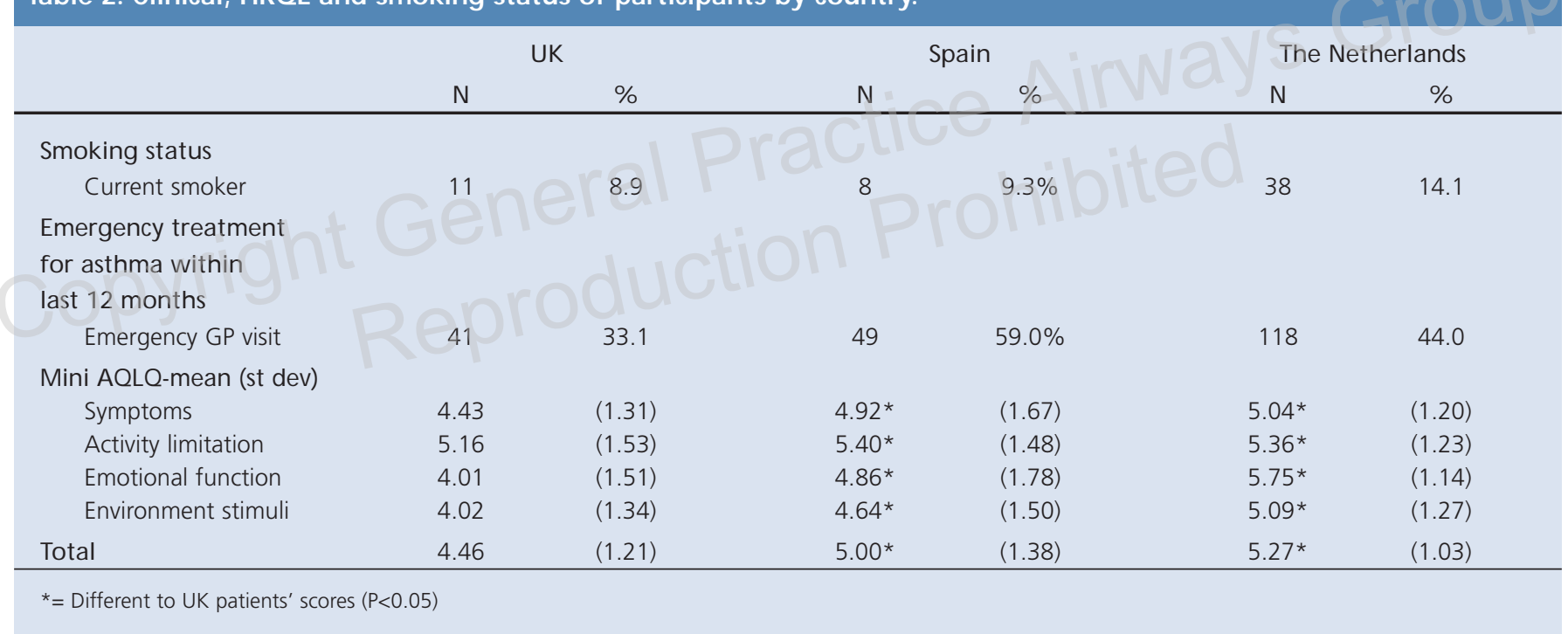

dataset because they did not meet study entry criteria (they were all under 18 years old). The majority of patients had evidence of persistent asthma as shown by the large proportion using combination inhalers (long acting betaagonist plus inhaled corticosteroids, 55\%) or inhaled corticosteroids alone (82\%).

\section{Choice data}

Analysis of the choice data indicated that people were consistent $(93.4 \%$ to $95.3 \%)$ and reliable $(78.2 \%$ and $81.4 \%)$ in their answers to questions. All of the attributes were significant predictors of choice, indicating that participants valued all of them in their choices (Table 3). Participants were willing to pay the highest amounts to avoid asthma attacks that required emergency medical care $(€ 109.48)$ and to avoid days with asthma symptoms ( $€ 35.26$ per day). Participants were willing to pay $€ 15.74$ to avoid a self-managed asthma attack which was higher than the willingness to pay to reduce days needing reliever medication or risk of side effects. In contrast, participants were not willing to pay very much to avoid commonly-encountered mild side effects (the side effect attribute was not designed to capture preferences around the more severe side effects that can occur with preventer inhalers).

\section{Modelling improvements in asthma}

The willingness-to-pay data allows for the estimation of how much patients value overall improvements in different aspects 
Table 3. Results of discrete choice experiment, showing willingness-to-pay values for unit shifts and $95 \%$ confidence intervals

\begin{tabular}{|c|c|c|c|c|}
\hline & Coefficient & $\mathrm{P}$ & WTP ( ) & $(95 \% \mathrm{Cl})$ \\
\hline $\begin{array}{l}\text { Number of days } \\
\text { of symptoms }\end{array}$ & -0.15074083 & 0.0001 & 35.26 & $(31.67,39.75)$ \\
\hline Days need reliever & -0.01686887 & 0.0001 & 3.95 & $(2.27,5.82)$ \\
\hline Chance of side effects (\%) & -0.01063963 & 0.0001 & 2.49 & $(1.88,3.17)$ \\
\hline $\begin{array}{l}\text { Number of } \\
\text { preventer inhalers }\end{array}$ & -0.06656885 & 0.0002 & 15.57 & $(7.12,24.68)$ \\
\hline Cost $(€)$ & -0.00427481 & 0.0001 & / & \\
\hline $\begin{array}{l}\text { Asthma attacks: } \\
\text { None to Attacks do not } \\
\text { require trip to Dr / hospital }\end{array}$ & -0.06728728 & 0.007 & 15.74 & $4.21,28.03)$ \\
\hline $\begin{array}{l}\text { Asthma attacks: } \\
\text { None to Attack require } \\
\text { emergency trip to } \mathrm{Dr} / \mathrm{ER}\end{array}$ & -0.46801688 & 0.0001 & 109.48 & $(96.75,125.15)$ \\
\hline
\end{tabular}

$\mathrm{N}=9,811$ Observations

Table 4. Estimates of participants' willingness to pay for shifting from a hypothetical poor asthma state or the actual median sample state to full control of their asthma symptoms.

\begin{tabular}{|c|c|c|c|c|c|c|c|c|}
\hline & $\begin{array}{c}\text { WTP } \\
\text { for unit } \\
\text { change } \\
(€)\end{array}$ & $\begin{array}{l}\text { Poor } \\
\text { asthma } \\
\text { state }\end{array}$ & $\begin{array}{c}\text { Sample } \\
\text { median } \\
\text { state }\end{array}$ & $\begin{array}{c}\text { Well } \\
\text { controlled }\end{array}$ & $\begin{array}{c}\text { Total } \\
\text { absence } \\
\text { of } \\
\text { asthma }\end{array}$ & $\begin{array}{c}\text { Shift } \\
\text { from poor } \\
\text { asthma } \\
\text { state to } \\
\text { total } \\
\text { absence } \\
\text { of asthma } \\
(€)\end{array}$ & $\begin{array}{c}\text { Shift } \\
\text { from study } \\
\text { sample } \\
\text { median } \\
\text { to total } \\
\text { absence } \\
\text { of asthma } \\
(€)\end{array}$ & $\begin{array}{c}\text { Shift } \\
\text { from well } \\
\text { controlled } \\
\text { to total } \\
\text { absence } \\
\text { of asthma } \\
(€)\end{array}$ \\
\hline Days need reliever & 3.95 & 5 days & 2 days & 2 days & 0 days & 19.75 & 7.90 & 7.90 \\
\hline Chance of side effects (\%) & 2.49 & $1 \%$ & $1 \%$ & $1 \%$ & $1 \%$ & 0 & 0 & 0 \\
\hline Number of preventer inhalers & 15.57 & 1 inhaler & 1 inhaler & 1 inhaler & 1 inhaler & 0 & 0 & 0 \\
\hline $\begin{array}{l}\text { Asthma attacks, but do not } \\
\text { require trip to Dr or hospital }\end{array}$ & 15.74 & N & Y & $\mathrm{N}$ & $\mathrm{N}$ & - & 15.74 & 0 \\
\hline $\begin{array}{l}\text { Asthma attacks require } \\
\text { emergency trip to } D r \text { or } E R\end{array}$ & & & & & Total & $€ 305.53$ & $€ 94.16$ & $€ 78.42$ \\
\hline
\end{tabular}

of their asthma. This is referred to as a 'welfare shift'. The value of moving to a total absence of asthma symptoms was estimated. The participants' current profile (described in terms of our attributes and levels) was used as one starting point, in addition to a hypothetical poorly-controlled state. The hypothetical poor asthma state was defined as five days per week with symptoms, five days per week needing reliever medication, side effects on $1 \%$ of days, one preventer inhaler, and an asthma attack that required an emergency visit to their doctor or hospital in the last twelve months. The willingness-to-pay amounts are estimated by simply determining the sum of the product of the attribute level shift (e.g. 5 days with symptoms to 0 days) and the willingness-topay value for a unit of that attribute.

The analysis indicates that asthma patients were willing to pay €94.16 per month to move from their current state 
(described in terms of the attributes) to a total absence of asthma. Participants were willing to pay $€ 78.42$ per month to shift from their current asthma state to full control of asthma, and $€ 305.53$ per month to move from the hypothesised poor asthma state to full control of asthma (Table 4). Wald tests revealed no statistically significant differences in the interacted coefficients based on low and high income.

\section{Discussion}

\section{Summary of main findings}

This study has collected patient preference data for asthma symptoms and therapy. People with asthma in three European countries all completed equivalent versions of a DCE survey. The DCE included five asthma-related attributes offset by the out-of-pocket cost attribute. These included number of days per week with symptoms, need for reliever medication, chance of mild side effects of preventer therapy (e.g. cough, tremor), number of preventer inhalers, and asthma attacks which either did or didn't require an unscheduled visit to a doctor or A\&E. The DCE captured patient preferences for these attributes; this was expressed in terms of willingness-topay values. The results from the three countries in terms of the relative importance of the attributes were very similar.

All of the attributes were significant predictors of choice, indicating that we were capturing patient preferences. The willingness-to-pay data indicated that the most important attribute was severe asthma attacks that required emergency visit to a GP or the hospital. Participants were willing to pay $€ 109$ per month to avoid this. The second most important attribute was the number of days per week with symptoms. This mirrors the findings from Johansson et al who reported that the number of symptom-free days per month was the most important attribute (their study did not include exacerbations). ${ }^{9}$ In contrast, some of the other attributes were much less important to participants. Participants were only willing to pay an extra $€ 3.95$ per month to reduce their need for reliever medication, which supports the view that people are quite comfortable relying on their short-acting betaagonist medication. Willingness to pay to avoid self-managed exacerbations was also quite low at only $€ 15.74$ per month. Participants were willing to pay even less to reduce their risk of mild side effects such as cough, tremor and palpitations (this didn't include the more severe side effects that can occur less commonly). The relative unimportance of side effects is not a general finding in DCE studies. In our previous work, we identified that people with epilepsy placed much greater importance on the avoidance of side effects than they did on improving their seizure control. ${ }^{29}$ This indicates that findings of these surveys could be disease-specific.

\section{Strengths and limitations of this study}

The study was designed as a European survey in an attempt to capture a broad scope of patient preferences. In addition, however, the three countries chosen have different systems in place for the payment of medication. Spain operates a co-pay system whereby the amount a patient pays depends on the price of the drug. In the UK, patients pay a set prescription fee regardless of drug price, and in the Netherlands patients pay nothing directly for their drugs. Participants in Spain were, on average, willing to pay more for their asthma medication than participants in the UK or Netherlands. The basic pattern of results in terms of the importance of the attributes compared to each other is similar for the three countries. The Spanish participants may have been willing to pay more because they are used to paying more for medication and implicitly better understand the concept that drug quality and price may be related. Alternatively, the results may reflect the mix of patients from each country. The different recruitment methods led to some variability, but also ensured that a wide range of patients were recruited into the study.

The study data were used to understand the value that people placed on improvements in their asthma. Participants' willingness to pay for moving from the sample average to a total absence of asthma symptoms was estimated. Assuming the median health state, participants were willing to pay $€ 94$ per month to move to a total absence of asthma. To shift from a hypothetical profile of poorly-controlled asthma to a total absence of asthma, participants were willing to pay $€ 305$ per month. Potentially any health state which can be described by the study attributes could be modelled in this way. It would also be possible to estimate the perceived benefits of new interventions, or even changes in clinical guidelines.

There are limitations with this study that should be noted. It is necessary to restrict the number of attributes that are included, and the choice of which to include is of course subject to bias. This means that we don't capture preferences for all aspects of asthma therapy, but just for our chosen attributes. We have tried to select attributes in an unbiased way, but there may well be other important aspects of asthma therapy that have not been included.

One other limitation of this research relates to the assumptions that are made about how people make decisions in a DCE. It is assumed that people trade between all of the attributes in the choice sets when making decisions, but such a complex approach to decision-making is not really consistent with evidence from cognitive psychology ${ }^{30}$. Due to the method required to elicit willingness-to-pay using marginal rates of substitution, a compensatory decision-making structure has to be assumed. In that respect, this study is the same as almost all other DCE studies in the literature. Some work has explored this issue but it remains unclear exactly how you could test for non-compensatory decision-making. ${ }^{31,32}$ What may appear to be compensatory decision-making at the aggregate level may 
be heuristic-driven at the individual level. But we have no basis in this study for understanding the nature of those heuristics and could only guess at what might be driving them. In addition, by their nature heuristics are idiosyncratic, so potentially could be unique to each person. If we accept this as a limitation, then we feel that the values themselves still indicate the relative importance of the different attributes and this is the most important finding from this study.

\section{Implications for future research or clinical practice}

Within GINA guidelines there is equal importance attached to the avoidance of side effects and the control of exacerbations. The findings of this study indicate that there exists a 40 -fold difference in patients' willingness to pay to avoid exacerbations compared to side effects. The much greater importance to patients of controlling exacerbations should be reflected in the GINA guidelines. We suggest that the GINA guidelines should incorporate a scoring mechanism which is based upon the importance of each outcome to patients. These results also predict that the management of asthma will most likely fail if it is aimed at improving an outcome on which patients place little or no value. It is clear that the importance of different outcomes varies between stakeholders, which may explain why some changes in asthma management are harder to implement. Indeed, the DCE approach may well be a very sensitive method for determining the effects of an educational programme for patients by examining the impact it has on patients' values. The DCE in this context could easily be treated akin to a measurement 'instrument' whereby shifts in attribute weights (i.e. values) can be tested using Wald tests of linear restrictions, akin to subgroups, and the sensitivity in essence actually measured.

This study has demonstrated the value that people with asthma place on the avoidance of symptoms and the burden related to asthma. This is a relatively large European study which we hope provides useful information for a potentially quite diverse range of stakeholders - from national reimbursement agencies to doctors and patients making decisions regarding asthma therapies. These data could also be used in guideline development to identify areas of most concern to patients.

\section{Acknowledgements}

The authors would like to acknowledge the help of Megan Stafford in preparing this manuscript and Scott Doyle for managing the study. The authors would like to acknowledge the time and support given to the study by the study participants who completed the questionnaires.

\section{Funding statement}

Funding for this study was provided by GlaxoSmithKline (GSK).

\section{Conflicts of interest}

Andrew Lloyd worked for United BioSource Corp when this study was completed and UBC undertake consulting for the pharmaceutical Industry. Emma McIntosh has no conflicts of interest. Klaus F Rabe has no directly relevant conflicts of interest. Angela Williams is an employee of GlaxoSmithKline R\&D.

\section{References}

1 Global Initiative for Asthma (GINA). Pocket Guide for Asthma Management and Prevention, 2004.

2 Rabe KF, Vermiere PA, Soriano JB, Maier WC. Clinical management of asthma in 1999: the Asthma Insights and Reality in Europe (AIRE) study. Eur Respir J 2000;16:802-07.

3 Bellamy D, Harris T. Poor perceptions and expectations of asthma control: Results of the International Control of Asthma Symptoms (ICAS) survey of patients and general practitioners. Prim Care Resp J 2005;14(5):252-8. doi:10.1016/j.pcrj.2005.04.003

4 Hayden ML, Johnson C, Dolan CM, Morris BM, Bleecker ER for the TENOR Study Group. High level healthcare utilization in severe and difficult-to-treat asthma. Poster presented at AAAAl, 2002.

5 Warschburger P, Busch S, Bauer CP, Kiosz D, Stachow R, Petermann F. Healthrelated quality of life in children and adolescent with asthma: results from the ESTAR Study. J Asthma 2004;41;463-70

6 Fulbrigge AL, Adams RJ, Guilbert TW, et al. The burden of asthma in the United States. Am J Respir Crit Care Med 2002;166:1044-9.

7 Osman LM, McKenzie L, Cairns J, et al. Patient weighting of importance of asthma symptoms. Thorax 2001;56:138-42.

8 Zillich AJ, Blumenschein K, Johannesson M, Freeman P. Assessment of the relationship between measures of disease severity, quality of life, and willingness to pay in asthma. Pharmacoeconomics 2002;20:257-65.

9 Johannsson G, Tornling G, Anderson S, Karlsson GS, Falt K, Berggren F. Asthma treatment preference study, a conjoint analysis of preferred drug treatments. Chest 2004:125:916-23

10 King MT, Hall J, Lanscar E, Fiebig D, Hossain I, Louviere J, Reddel HK, Jenkins CR. Patient preferences for managing asthma: results from a discrete choice experiment. Health Econ 2007;16:703-17.

11 Slothuus Skjoldborg U, Gyrd-Hansen D. Conjoint analysis. The cost variable: an Achilles' heel? Health Econ 2002;12:479-91.

12 Small KA, Rosen HS. Applied Welfare Economics with Discrete Choice Models. Econometrica 1981;49:105-30

13 Hanemann WM. Welfare evaluations in contingent valuation experiments with discrete responses. Am J Agric Econ 1984;66:332-41.

14 Johnson FR, Banzhaf MR, Desvousges WH. Willingness to pay for improved respiratory and cardiovascular health: a multiple format stated-preference approach. Health Econ 2000;9:295-317.

15 Johnson FR, Desvousges WH, Ruby M, Stieb D, De Civita P. Eliciting stated health preferences: an application to willingness to pay for longevity. Med Decis Making 1998;18:s57-s67.

16 Lancsar E, Savage E. Deriving welfare measures from discrete choice experiments: inconsistency between current methods and random utility and welfare theory. Health Economics Letters 2004;13:901-07.

17 Lancsar E, Savage E. Deriving welfare measures from discrete choice experiments: a response to Ryan and Santos Silva. Health Economics Letters 2004; 13:919-24.

18 Ryan M, Deriving welfare measures in discrete choice experiments: a comment to Lancsar and Savage (1). Health Economics Letters 2004;13:909-12.

19 Ratcliffe J. The use of conjoint analysis to elicit willingness-to-pay values. Proceed with caution? Int J Technol Assess Health Care 2000;16:270-5.

20 McIntosh E, Ryan M. Using discrete choice experiments to derive welfare estimates for the provision of elective surgery: implications of discontinuous preferences. J Econ Psychol 2002;23:367-82.

21 Santos Silva JMC. Deriving welfare measures in discrete choice experiments: a comment to Lancsar and Savage (2). Health Economics Letters 2004;13:913-18.

22 Sculpher M, Bryan S, Fry P, de Winter P, Payne H, Emberton M. Patients' preferences 
for the management of non-metastatic prostate cancer: discrete choice experiment BMJ 2004;328:382-6. doi:10.1136/bmj.37972.497234.44.

23 Ryan M, Farrar S. Using conjoint analysis to elicit preferences in health care. BMJ 2000;320:1530-3.

24 Louviere J, Hensher DA, Swait J. Stated Choice Methods: analysis and application. Cambridge: Cambridge University Press, 2000.

25 Juniper EF, Guyatt GH, Cox FM, Ferrie PJ, King DR. Development and validation of the mini asthma quality of life questionnaire. Eur Respir J 1999;14:32-38.

26 Schkade DA, Payne JW. How people respond to contingent valuation questions: A verbal protocol analysis of willingness to pay for an environmental regulation. J Environ Econ Manage 1994;26:88-109.

27 Eremenco S. The functional assessment of chronic illness therapy multilingual translations project. ATA Chronicle 1999;35-41

28 Green W. LIMDEP Version 8, Users Manual. Econometric Software Inc, 1998.

29 Lloyd AJ, Mclntosh E, Price M. The importance of drug adverse effects compared with seizure control for people with epilepsy: a discrete choice experiment. Pharmacoeconomics 2005;23:1167-81.

30 Gigerenzer G, Todd P, ABC Research Group (Eds). Simple heuristics that make us smart. Evolution and Cognition (416 edn), Stich S (Ed). Oxford University Press: New York, 1999.

31 Lloyd AJ Threats to the estimation of benefit: Are preference elicitation methods accurate? Health Econ 2003;12(5):393-402.

32 Cairns J, van der Pol M, Lloyd AJ, Decision making heuristics and the elicitation of preferences. Health Econ 2002;11:655.

\section{Available online at http://w w w.thepcrj.org}

